\title{
Emerging Street Youth Violent Groups in Musoma: What is the Role of Individual Parents' Socio-Economic Status (SES)?
}

\author{
Faustine Bwire Masath ${ }^{1}$
}

\begin{abstract}
This study presents findings regarding violence among emerging street youth violent groups in Musoma, Tanzania using a total sample of $94(\mathrm{M}=20.02$ years, $\mathrm{SD}=4.05)$ respondents purposefully selected from four violent groups. Specific objectives included: examining the variation in violence involvement among the violent groups; establishing the level of relationship between individual parents' SES and the level of violent behaviour among the members of the violent groups; and examining to determine if individual parents' SES is a significant predictor of the development of violence among members of the violent groups. Findings revealed higher level of involvement in violent behaviours among groups $(\mathrm{M}=$ $70.85, \mathrm{SD}=11.14)$. The ANOVA results indicated a statistical significant difference $[\mathrm{F}(3$, $90)=6.035, p=0.001]$ in the mean scores of the level of involvement in violent behaviour among the violent groups comprised of members drawn from different socio-economic status. The contribution of parents' socio-economic status (SES) on individual's violent behaviours measured by multiple regression analysis was weak $\left(\mathrm{R}^{2}=.112, \mathrm{p}=.161\right)$. Thus, parents' SES is a weak and non-statistical significant predictor for individual's involvement in violence and violent acts. Thus, immediate intervention programmes such as establishment of rehabilitation centres and counselling services is recommended.
\end{abstract}

Keywords: youth; youth violence; aggression; SES, Musoma; Tanzania

DOI: $\underline{\text { https://doi.org/10.37759/mjed.2017.1.1.5 }}$

\section{Introduction}

Aggression and violence issues in the field of psychology are increasingly becoming topical issues calling for research. Although the two terms may contain a literally similar semantic meaning, yet the two are not synonymous and cannot be used interchangeably. Violence can easily be studied through the study of aggression because it is an act of aggression. Rahman and Huq (2005) define aggression as an action, which is visible in overt behaviour that constitutes three elements: intention, action tendency and actual harm committed to another person. Aggression is an intentional injury of or harm to another person (Radigan, 2002). Papalia, Olds and Feldman (2004) grouped aggression into four types: instrumental aggression (aggression used as an instrument to reach a goal); hostile aggression (action intended to hurt another person); overt aggression (physical or verbal aggression openly directed to its target); and, relational aggression (aggression aimed at damaging or interfering with another person's relationships, reputation, or psychological well-being). The definitions above bear similar characteristics related to aggression, i.e., deliberate action and cause harm to another person. Different theories have been developed to explain the root cause of

${ }^{1}$ Educational Psychology and Curriculum Studies Department, Dar es Salaam University College of Education, P.O. Box 2329, Dar es Salaam. 
aggression including the Evolutionary Theory; the Social Learning Theory (Santrock, 2005) and the Drive Theory (Smith, 2008).

Aggression and violence have been associated with a number of causes in literature. For example, Papalia et al. (2004) explain that aggression and violence may have their root in an individual's biological make up (genetic inheritance); psychological factors such as high level of temperament (intense emotional and low self-esteem); environmental factors such as stressful and un-stimulating home atmosphere; harsh disciplinary actions; lack of maternal warmth and social support; exposure to aggressive adults and neighbourhood violence; and transient peer groups which prevent stable friendship, as well as culture. Studies also show a significant relationship between violent behaviours and individuals' demographic factors such as gender, age, parent marital status, and socio-economic status (Barzman, Brackenbury, Sonnier, Schnell, Cassedy, Salisbury, Sorter \& Mossman, 2011; Eroglu, 2009). Barzman et al. (2011) revealed that age is inversely related to the likelihood of aggression and violence. The more an individual's age increases, the less the likelihood of aggression and violence. Additionally, Matthews, Flory, Muldoon and Manuck (2000) found that socio-economic status correlates with the development of aggressive behaviour in children. Children from lower socio-economic status families are more likely to demonstrate aggressive behaviour than their counterpart from high socio-economic status families. It is also revealed by Wahl and Metzner (2012) that the family income and the educational level of the mother influence the children's aggressiveness due to knowledge deficits.

Globally, individuals or nations have suffered from the effects of aggression and violent behaviours of youth violent groups. For instance, in America, the $18^{\text {th }}$ street gang formed in Los Angeles by a group of second-generation young Hispanics has been engaging in different crimes including kidnapping, trafficking, robbery, etc ("18th Street Gang, n.d."). In South Africa, the Americans, the Hard Livings, and the Junky Funky Kids youth gang groups among the many gangs located in the Western Cape, have been reported as the most youth violent groups involved in different crime among of them being drug trafficking (Manenberg, 2012). The destructive and harmful violent actions such as war, terrorism, assassination, insult and verbal assault are associated with aggressive behaviour of the youth violent groups (Baumeister, Smart \& Boden, 1996). Other aggressive and violent behaviours may comprise rape [Rahman \& Huq, 2005; United Nations Office on Drugs and Crimes (UNODC, 2012)]; bullying and school violence (Dougherty, 2009; Poipoi, Agak \& Kapuka, 2011); killings (Uwasomba, 2009); as well as robbery and physical assault (Bartol, 1991; Ramírez \& Andreu, 2005).

\subsection{Violence and Violent Acts in Musoma}

Various forms of violence and violent actions have been commonly reported in Tanzania. Apart from other violent issues that have been reported such as the rate of domestic violence which has increased rapidly from $5.06 \%$ in 2002 to $10.66 \%$ in 2007 (URT, 2010), rape, killings, sexual harassment, theft and robbery in Tanzania (Andersson \& Stavrou, 2000; Liviolenta, 2012; Nassor, 2012), youth violence is also one of the emerging violent issues that the Tanzania currently is facing in many parts of 
the country. A number of street youth violent groups have been reported, namely: Mbio za Vijiti, Jamaica Mockers, etc. (ITV, 2012), Panya road (Nachilongo, 2016) as formed in various regions by youth and children with a range of different demographic characteristics. Researcher's anecdotal evidence shows that most of the members in these groups are those who dropped out of school, and street children. The groups exist in an unorganized or informal manner in such a way that they look like they have no leader leading the group. They also roam on the streets as if they have no common or specific place for meeting. The emergence of youth violent groups is attributed to, among other factors, the individuals' socio-economic status, lack of education, and an increased rate of social immorality. However, these are factors that need to be investigated in relation to the Tanzanian socio-cultural context.

Mara is one of the regions in Tanzania most likely affected by aggressive behaviours. The bloody killings of 17 people in Buhare ward in Musoma (Magubira \& Mayunga, 2010) and the emerging street youth violent groups are examples of aggressive behaviours in Mara region as reported by ITV (2012). The youth violent groups in Mara region emerged in early 2000s in the street of Nyakato after Mbio za Vijiti group was heard as engaged in robbery and theft. The actual number of members could not be known; however, the number could range from 30-50 (according to the respondents). The gangs normally moved in small groups of 5 to 10 members when in a mission or in a social gathering. However, despite this clue it is difficult to identify and find them altogether at once. It was also noted that the groups were formed purposely to defend group members and friends from fights or from being attacked in disco clubs, parties and in some other social gatherings. However, late on, the purpose for forming the groups changed from being self-defence to robbery, attack and theft in disco clubs, other social gatherings and on the streets. Other groups that followed the same suit included: Mbio za Vijiti, Mdomo wa Furu, Jamaica Mockers and West Lawama from other wards.

The formation of other violent youth groups intensified fights and rage between groups especially in social gatherings such as disco clubs and parties. Thus, frequent fights, robbery and theft emerged in the town involving members of the named groups. However, their actions have now gone beyond rival groups within the confinement to a wider scope of the community. The escalating violent actions involving members of the youth violent groups caused not only fear and insecurity to the town's residents and visitors, but also these violent groups have led the community into a place with frequent fights, attacks, injuries and sometimes deaths among members of the violent groups (ITV, 2012). Thus, violent groups not only in Mara but also in other parts of Tanzania are emerging as a challenge that needs to be addressed to restore peace and tranquillity among members of the community. Understanding the motive behind forming the violent groups, and their level of violence could form an important step in finding a mechanism that would help in reducing or eradicating the problem.

\subsection{Research Objectives and Hypotheses}

The study was guided by three research objectives which were: to examine the variation in violence involvement among the violent groups; to establish the level relationship 
between individual parents' SEs and the level of violence behaviour among the members of the violent groups; and to examine if individual parents' SES is a significant predictor of the development of violence among members of the violent groups. Three research hypotheses which guided the study are:

1. There is a significant difference in the level of violence behaviour between the violent groups;

2. There is a relationship between parents' socio-economic status and the level of violence behaviours among the members of the violent groups; and,

3. Parents' socio-economic status is significant predictor of the development of violence behaviour among violent groups' members.

Data reported in this article are part of the researcher's master's dissertation of the research conducted in 2013. The researcher understands that time has elapsed and the data may not represent the current crime situation caused by youth violence in the studied area. The emergence of youth violent groups in Dar es Salaam region such as Panya road suggests the need for addressing the problem and find out research-based evidence that can help to restrain the problem.

\section{Methodology}

The study employed a descriptive research design to achieve the research objectives. Based on the nature of the study, respondents were purposely selected from the four violent groups after the researcher was directed by other youth obtained in social gatherings and other areas such as men's salons and football grounds in the streets of Kamunyonge, Mwisenge, Nyakato and Nyamatare wards where most youth street violent members lived. The researcher had to talk in privacy with the violent group members identified seeking for their consent to participate in the study.

Apparently, it was difficult to get much of the target participant seven after giving adequate explanation regarding the purpose of the study and assuring them confidentiality. Most of the members had fear in providing information related to their engagements assuming that they could expose themselves and their groups into risks. Following the difficulties faced, the researcher decided to involve two research assistants who were familiar with members of violent groups to obtain facilitate the key information for the study. The assistants were two young men who were Form IV leavers, one from Kamunyonge and another from Nyakato Wards. The assistants were trained on the questionnaire and research ethics. However, the assistants were only responsible for soliciting target members and facilitating meetings with the researcher. Thus, the filling-in the questionnaires was done only after the respondents were given instructions by the researcher. In this way, members of the violent groups agreed to participate in the study were requested to fill in the questionnaires instantly and submit to the researcher. This strategy helped to obtain a total of 94 members from four violent groups (see Table 2). 
A questionnaire was designed in a format adopted and modified from the Multisite Violence Prevention Project (2004) scale which measures the number of times an individual has been involved in physical, non-physical and relational aggression in the past 30 days. It consisted of 20 items. For example, in the last 30 days, how many times have you thrown something at someone to hurt them? Insulted someone's family? Spread a false rumour about someone? The items were answered along 6 points ranging from 1 (never) to 6 (20 times and above). Cronbach's alpha coefficient was calculated for the scale and internal consistency of 0.89 alpha value was obtained. Coding of data was done using the IBM Statistical Package for Social Science (SPSS) version 21.0. In analysis of data, the frequency rating for 20 scale items was added to obtain a total number of times an individual was involved in aggressive behaviour. The One-way Analysis of Variance (ANOVA) was used to examine the difference in the level of aggressive behaviour between the four violent groups. Pearson product-moment correlation coefficient was run to test the relationship between parents' socio-economic status and the level of aggressive behaviour among members of the violent groups. In addition, multiple regression analysis was performed to examine the influence of parents' socio-economic status (marital status, education level and occupation) to the development of aggressive behaviour among members of the violent groups.

\section{Results}

Individual youth's involvement in violence and violent acts was calculated using mean and standard deviation as measures of central tendency. Results revealed mean score $(M=70.85, S D=11.14$; Range $=68)$ on total violent behaviour scale implying that a total number of violent behaviours one can engage in violent acts over the past 12 months' time. The One-way Analysis of Variance (ANOVA) was conducted to the violent groups (4 levels) as an independent variable and violence behaviour as a dependent variable. Brown-Forsythe assumption was calculated and met $[F(3,64.28)=6.035$, $p=.001]$. Results indicated a statistical significant difference $[F(3,90)=6.035$, $M S e=106.75, p=.001]$ found in the mean scores of the four violent groups at $p<0.05$ level (2-tailed). The effect size calculated was moderate $\left(\eta^{2}=0.17\right)$. Hence, the alternative hypothesis that there is a significant difference in the level of violent behaviour between the violent groups was accepted. Post-hoc analysis Tukey HSD was conducted to identify the differences between the mean score of the four violent groups. A statistical significant difference was found in the level of violence between Mbio za Vijiti violent group $(M=76.38, S D=10.62)$ and the West Lawama group $(M=63.95$, $S D=5.31 ; p=.000)$. A statistical significant difference was also revealed between the mean scores for Jamaica Mockers group $(M=72.45, S D=7.88)$ and the West Lawama group $(M=63.95, S D=5.31 ; p=.038)$. 
Table 1: Demographic characteristics

\begin{tabular}{|c|c|c|c|c|c|c|}
\hline No. & Variables & & $\mathrm{f}$ & Percentage & Mean (M) & $\begin{array}{l}\text { Standard } \\
\text { Deviation (SD) }\end{array}$ \\
\hline \multirow[t]{2}{*}{1.} & \multirow[t]{2}{*}{ VG Members'sex } & Male & 94 & 100 & & \\
\hline & & Female & - & - & & \\
\hline 2. & VG Members’ age & & 94 & 100 & 20.02 & 4.05 \\
\hline \multirow[t]{2}{*}{3.} & \multirow[t]{2}{*}{ VG Members' Education level } & Primary Education & 27 & 28.7 & & \\
\hline & & Secondary Education above & 67 & 71.3 & & \\
\hline \multirow[t]{2}{*}{4.} & \multirow[t]{2}{*}{ VG Members’ Marital status } & Single & 76 & 80.9 & & \\
\hline & & Married & 18 & 19.1 & & \\
\hline \multirow[t]{4}{*}{5.} & \multirow[t]{4}{*}{ Number of members used from each violent group } & Mbio za Vijiti & 26 & 27.7 & & \\
\hline & & Mdomo wa Furu & 24 & 25.5 & & \\
\hline & & Jamaica Mockers & 22 & 23.4 & & \\
\hline & & West Lawama & 22 & 23.4 & & \\
\hline \multirow[t]{4}{*}{6.} & \multirow[t]{4}{*}{ VG Members' Parents marital status } & Single/unmarried & 3 & 3.2 & & \\
\hline & & Married & 67 & 71.3 & & \\
\hline & & Divorced & 10 & 10.6 & & \\
\hline & & Widowed & 14 & 14.9 & & \\
\hline \multirow[t]{2}{*}{7.} & \multirow[t]{2}{*}{ VG Members' father occupation status } & Employed & 48 & 51.1 & & \\
\hline & & Unemployed & 46 & 48.9 & & \\
\hline \multirow[t]{2}{*}{8.} & \multirow[t]{2}{*}{ VG Members' mother occupation status } & Employed & 60 & 63.8 & & \\
\hline & & Unemployed & 34 & 36.2 & & \\
\hline \multirow[t]{2}{*}{9.} & \multirow[t]{2}{*}{ VG Members' father education level } & Primary school and below & 34 & 36.2 & & \\
\hline & & Secondary school and above & 60 & 63.8 & & \\
\hline \multirow[t]{2}{*}{10.} & \multirow[t]{2}{*}{ VG Members' mother education level } & Primary school and below & 42 & 44.7 & & \\
\hline & & Secondary school and above & 52 & 55.3 & & \\
\hline
\end{tabular}

Key: VG= Violent Group 
However, no statistical significant difference was found in the level of aggressive behaviour between Mdomo wa Furu violent members $(M=69.67, S D=14.59)$ and in the other three violent groups as summarised in Table 2.

Table 2: Tukey HSD Results

\begin{tabular}{|c|c|c|c|c|}
\hline $\begin{array}{l}\text { I (Violent Group's } \\
\text { Name) }\end{array}$ & J (Violent Group's Name) & $\begin{array}{l}\text { Mean Difference } \\
(\mathrm{I}-\mathrm{J})\end{array}$ & $\begin{array}{l}\text { Std. } \\
\text { Error }\end{array}$ & $\begin{array}{l}\text { Significant } \\
\text { Value. }\end{array}$ \\
\hline \multirow[t]{3}{*}{ Mbio za Vijiti } & Mdomo wa Furu & 6.718 & 2.925 & 0.106 \\
\hline & Jamaica Mockers & 3.930 & 2.993 & 0.557 \\
\hline & West Lawama & $12.430 *$ & 2.993 & 0.000 \\
\hline \multirow[t]{3}{*}{ Mdomo wa Furu } & Mbio za Vijiti & -6.718 & 2.925 & 0.106 \\
\hline & Jamaica Mockers & -2.788 & 3.050 & 0.797 \\
\hline & West Lawama & 5.712 & 3.050 & 0.247 \\
\hline \multirow[t]{3}{*}{ Jamaica Mockers } & Mbio za Vijiti & -3.930 & 2.993 & 0.557 \\
\hline & Mdomo wa Furu & 2.788 & 3.050 & 0.797 \\
\hline & West Lawama & $8.500 *$ & 3.115 & 0.038 \\
\hline \multirow[t]{3}{*}{ West Lawama } & Mbio za Vijiti & $-12.430 *$ & 2.993 & 0.000 \\
\hline & Mdomo wa Furu & -5.712 & 3.050 & 0.247 \\
\hline & Jamaica Mockers & $-8.500 *$ & 3.115 & 0.038 \\
\hline
\end{tabular}

*. The mean difference is significant at the 0.05 level

The relationship between parents' socio-economic status (marital status, education level and occupation) and the level of aggressive behaviours among the members of the violent groups as measured by multisite violence prevention project aggressive scale was investigated using Pearson product-moment correlation coefficient. Preliminary analyses were conducted to ensure no violation of normality, linearity and homoscedasticity. There was no statistical significant relationship between the variables which indicated low or negligible association between parents' socio-economic status and the level of violence among the members of the violent groups. Thus, the alternative hypothesis that there is a relationship between parents' socio-economic status and the level of violence among members of the violent groups was rejected (Table 3).

Table 3: Pearson product-moment correlation between parents' socio-economic status and the level of violence among members of the violent groups

\begin{tabular}{ll}
\hline \multirow{2}{*}{ Parents' Socio-economic Status Variables } & Correlation Coefficient (r) \\
\cline { 2 - 2 } Marital Status & Level of violent behaviour (Total Violence) \\
Father's Education & 0.031 \\
Mother's Education & 0.055 \\
Father's Occupation & 0.134 \\
Mother's Occupation & -0.059 \\
\hline
\end{tabular}

Multiple regression analysis was conducted to examine the influence of parents' socio-economic status to the development of violent behaviours among the members of the violent groups. Collinearity assumption was met in all independent variables with tolerance value $>.10$ as suggested by Pallant (2010). The result indicated that parents' socio-economic status variables are not statistical significant predictors for the development of violence among members of the violent groups. Hence, the alternative hypothesis that parents' socio-economic status is a significant predictor for the development of violent behaviours among the members of the violent groups was rejected (Table 4). 
Table 4: Multiple regression analysis of test the influence of parents' socio-economic status on development of violent behaviours among members of the violent groups.

\begin{tabular}{llll}
\hline & $\begin{array}{l}\text { Standardized } \\
\text { Coefficients }\end{array}$ & T & Significant Value \\
\hline & Beta & & (2-tailed). \\
Parents' Marital Status & 0.037 & 0.345 & 0.731 \\
Father's Education Level & -0.087 & -0.554 & 0.581 \\
Mother's Education Level & 0.183 & 1.221 & 0.225 \\
Father's Occupation & -0.023 & -0.202 & 0.841 \\
Mother's Occupation & 0.020 & -0.170 & 0.866 \\
\hline
\end{tabular}

\section{Discussion}

Findings obtained from analysis techniques employed such as ANOVA indicate that, there is a significant difference in the level of violence between the violent groups. This confirmed the study's first hypothesis. Within the four studied violent groups, Mbio za Vijiti members led in violent behaviour followed by Jamaica Mockers and Mdomo wa Furu members. The results reflect what ITV (2012) reported, that, the group located in Nyakato area is the most dangerous group involved in robbery, rape, killings and other forms of violence though other groups' level of violence cannot be ignored. It appears that the higher level of violent behaviour indicated by members of the violent groups is an alarming indicator for the development of illegal actions such as theft, robbery and killings in the Musoma municipality as also revealed by Andersson and Stavrou (2000). Thus, the finding suggests intervention programmes to curb the situation and reduce youths' violence and involvement in violent actions. The role of government authorities in combating these behaviours remains vital.

The current study also shows that the level of violence demonstrated by members of the violent groups does not significantly relate to their parents' socio-economic status. This denies the assumption that, individuals who come from single parent families are likely to be more violent or aggressive than those from families with married parents. The finding further suggests that parents' education level is linked to the children's violent and aggressive behaviour development though it indicated a weak correlation $(r=.134)$. Consistent with the social learning theory of aggression as advocated by Bandura (Santrock, 2005), the correlation coefficient obtained between the two variables infers that the development of violent behaviours among members of the violent groups might have been influenced by other factors such as peer pressure and imitation from others.

It also appears that, family with low socio-economic status (in this study represented by parents' occupation) does not necessarily imply children's higher level of involvement in violent behaviours. Thus, the findings of the current study do not corroborate the evidence presented on aggression and violence in the studies by of Flexon, Greenleaf and Lurigio (2012) who found that, involvement in violent behaviours is associated with family structure such as being reared by single or married parents. The difference in findings between these two studies might be attributable to rearing practices and existing socio-economic status and contexts prevailing in the two areas studies. Despite the fact that majority of the group members were from families with married couples, parental child rearing practices and negligence towards children education and developmental issues such as friendship and peer group formation can be the main cause to why children engage in violent groups and behaviours. Parents were reluctant in guiding their children on academic matters, career counselling and friendship that would better outcomes by exposing their children into freedom that made them to partner with children from families with different behavioural characteristics. Indeed, parents had improved their ways of child-rearing, children and youth involvement in violent groups could be reduced. 
The findings in the current study are also different from what Rahman and Huq (2005) who reported that children from low socio-economic status families are more aggressive than those from middle and higher socio-economic status. In this study, parents' occupational status had no statistically significant influence on the development of violent behaviours among members of the violent groups in studied area. The findings have shown that most of the members' parents were employed. However, parents' level of economic status was not computed on economic bases. The study also learned that it is it could not be clear if these violent group members had the assurance of basic needs such as food, clothes and shelter.

Furthermore, descriptive statistics showed that with parents' occupation status, majority members of the violent groups could get access to education. Thus, most of the members could be at secondary school or colleges by the time the study (see Table 1). This also suggests that, other factors apart from parents' socio-economic status, may have contributed to individual group member's involvement in violent behaviours as asserted in the existing theories of aggression. For instance, the social learning theory of aggression advocated by Bandura (Santrock, 2005), regards aggression as highly influenced by learning through imitation from other models and values placed to that action.

Nevertheless, the findings in the current study are different from that of Griffin, Botvin, Scheier, Diaz and Miller (2000) who found that children who come from single parent families engage more in problematic behaviours. The nature of respondents and the contextual differences might have influenced the change in findings as the current study employed a sample of 94 violent group members with different demographic characteristics regardless of their socio-economic status. The descriptive statistics revealed that most of the members' parents were married couples. Respondents involved in the current study were both students and non-students found in the violent groups.

\section{Conclusion and Recommendations}

This study describes and presents findings on violence among members of the violent groups in Musoma, Tanzania. The findings have shown that youth involvement in violent behaviours is increasing. Unlike other studies, the current study has found that there is no statistically significant influence between youth violence and their parents' socio-economic status of young men involved in violence and violent acts. However, the difference in the levels of violence between the violent groups was found. Inferring from the findings, the study suggests for intervention programmes such as establishment of rehabilitation centres; youth entrepreneur clubs; introduction of peer-group counselling to reduce the constantly increasing level of violence and violent acts among youth groups in Musoma and Tanzania at large. However, in the current study, there might be some relevant information that could not be obtained due the approach used and so this limitation that might have reduced the attainment of some goals for the study. The adoption of qualitative research using ethnographic design can be thought for future research. 
References

$18^{\text {th }}$ Street Gang. n.d. retrieved on the $18^{\text {th }}$ of May, 2015 from http://www.wow.com/wiki/18th Street gang?s pt=aolsem\&s chn=185.

Andersson, C., \& Stavrou, K. (2000). Youth Delinquency and the Criminal Justice System in Dar es Salaam, Tanzania: A Snapshot Survey, 2000. Retrieved on $23^{\text {rd }}$ of February, 2013 from http://cfsc.trunky.net/_uploads/Publications/Youth_Delinquency_and_the_Criminal_J ustice System in Dar es Salaam.pdf.

Bartol, C. R. (1991). Criminal behaviour: A psychosocial approach. Englewood, New Jersey: Prentice-Hall.

Barzman, D. H., Brackenbury, L., Sonnier, L., Schnell, B., Cassedy, A., Salisbury, S., Sorter, M., \& Mossman, D. (2011). Brief rating of aggression by children and adolescents (BRACHA): Development of a tool for assessing risk of inpatients' aggressive Behaviour. The Journal of the American Academy of Psychiatry and the Law, 39 (2), $170-179$.

Baumeister, R. F., Smart, L., \& Boden, J. M. (1996). Relation of threatened egotism to violence and aggression: The dark side of high self-esteem. Psychological Review, 103 (1), 5 33.

Dougherty, C. (2009). Teenage gunman kills 15 at school in Germany. The New York Times. Retrieved on $20^{\text {th }}$ of November, 2012 from http://www.nytimes.com

Eroglu, S. (2009). Dimensions of aggression behaviour and related demographic factors: A comparative study on high school students and university students. [Abstract]. Paper presented at the 3rd International Technology, Education and Development Conference, Valencia, Spain, 9-11 March, 2009. Retrieved on 11 ${ }^{\text {th }}$ of October, 2012 from http://library.iated.org/view/EROGLU2009DIM.

Flexon, J. L., Greenleaf, R. G. \& Lurigio, A. J. (2012). The Effects of Self-Control, Violent Membership, and Parental Attachment/Identification on Police Contacts among Latino and African American Youths. International Journal of Offender Therapy and Comparative Criminology, 56 (2), 218 - 238. DOI: 10.1177/0306624X10394116.

Griffin, K. W., Botvin, G. J., Scheier, L. M., Diaz, T., \& Miller, N. L. (2000). Parenting practices as predictors of substance use, delinquency, and aggression among urban minority youth: Moderating effects of family structure and gender. Psychological Addictive Behaviour, 14 (2), 174 - 184. Abstract retrieved on 20 th March, 2013 from http://www.ncbi.nlm.nih.gov/pubmed/10860116.

Independent Television (ITV) Broadcasting. 20:00pm news hour report by George Marato on the $21^{\text {st }}$ of March, 2012. IPP. Dar es Salaam.

Liviolenta, L. (2012). New robbery styles hits Dar. The Citizen. Retrieved on $27^{\text {th }}$ of September, 2012 from http://jabashadrack.blogspot.com/2012/09/new-robbery-style-hitsdar.html?m=1

Magubira, P., \& Mayunga, A. (2010). 17 buried amid a flood of tears. The Citizen. Retrieved on $18^{\text {th }}$ of February, 2010 from http://allafrica.com/stories/201002180859.html 
Manenberg (2012). Gang warfare: The government is unsure how to tackle the present plague of gang violence. Retrieved on $15^{\text {th }}$ of July, 2015 from http://www.economist.com/node/21560313.

Masath, F. B. (2013). Moral Deterioration: The reflection on Emerging Street Youth Gangs in Musoma, Tanzania. Academic Research International, 4 (1), 101-111.

Matthews, K. A., Flory, J. D., Muldoon, M. F., \& Manuck, S. B. (2000). Does socioeconomic status relate to central serotonergic responsivity in healthy adults? Psychosomatic Medicine, 62, $231-237$.

Multisite Violence Prevention Project. (2004). Retrieved on November 1, 2012 from www.cdc.gov/ncipc/pub-res/pdf/YV/CDC YV SecIII.pdf.

Nassor, A. (2012). Two charged with rape in Dar. The Daily News. Retrieved on $9^{\text {th }}$ of March, 2013 from http://www.dailynews.co.tz.

Nachilongo, H. (2016). Police arrest more than 15 "Panya Road". The Citizen. Retrieved on $20^{\text {th }}$ October, 2016 from http://www.thecitizen.co.tz/News/Police-arrest-more-than-15-Panya-Road-/1840340-3423128-9n8drxz/index.html

Pallant, J. (2010). SPSS survival manual. A step by step guide to data analysis using the SPSS program, $4^{\text {th }}$. Ed. New York: McGraw Hill.

Papalia, D. E., Olds, S. W., \& Feldman, R. D. (2004). A child's world: Infancy through adolescence, $9^{\text {th }}$ Ed. New York: McGraw Hill.

Poipoi, M. S., Agak, J. O., \& Kabuka, E. K. (2011). Perceived home factors contributing to violent behaviour among public secondary school students in western province, Kenya. Journal of Emerging Trends in Educational Research and Policy Studies, 2 (1), 30 40.

Radigan, B. L. (2002). Student study guide for use with Understanding Psychology, $6^{\text {th }}$ Edition by Feldman, R.S. New York: McGraw Hill.

Rahman, A. K. M. R., \& Huq, M. M. (2005). Aggression in adolescent boys and girls as related to socio-economic status and residential background. Journal of Life Earth Science, 1 (1), 5 - 9 .

Ramírez, J. M., \& Andreu, J. M. (2005). Aggression and some related psychological constructs (Anger, Hostility, and Impulsivity). Some comments from a research project. Neuroscience Bio-behavioural Review, 21(1) Retrieved on 30 ${ }^{\text {th }}$ of May, 2012 from http://eprints.ucm.es/8425/2/Aggression JMR revised-1.pdf.

Santrock, J. W. (2005). A topical approach to life-span development, $2^{\text {nd }}$ Edition. New York: McGraw Hill.

Smith, A. K. (2008). Theories of aggression. Retrieved on $9^{\text {th }}$ of March, 2013 from http://serendip.brynmawr.edu/exchange/node/1809.

United Nations Office on Drugs and Crimes (UNODC). (2012). World Report.

United Republic of Tanzania (URT). (2010). Tanzania Gender Indicators. 
Uwasomba, C. (2009). A socio-psychological exploration of Fyodor Dostoyevsky's crime and punishment. Educational Research and Review, 4 (4), 141 - 147.

Wahl, K. \& Metzner, C. (2012). Parental Influences on the prevalence and development of child aggressiveness. Journal of Child and Family Studies, 21 (2), 344 - 35. 